\title{
Red Imported Fire Ants and Their Impacts on Wildlife ${ }^{1}$
}

\section{Emma Willcox and William M. Giuliano²}

Two species of fire ant are found in Florida, the notorious red imported fire ant (RIFA; Solenopsis invicta; Figure 1) and the less common native fire ant (Solenopsis geminata).

RIFA were introduced to the U.S. through the port of Mobile, Alabama in the mid-to-late 1930s. Today, they infest more than 320,000,000 acres in Alabama, Arkansas, California, Florida, Georgia, Louisiana, Mississippi, New Mexico, North Carolina, Oklahoma, South Carolina, Tennessee, and Texas. The species continues to spread into areas of North America with suitable food sources, a mild climate, and adequate moisture. Due to their aggressive behavior and ferocious sting, threats they pose to humans and wildlife, and damage they cause to several agricultural commodities, RIFA are considered a major public nuisance.

RIFA are native to South America, where their abundance is restricted by competition with other ant species, predation, parasites, and pathogens (disease-causing bacteria and viruses). A lack of these natural enemies is thought to be one factor allowing RIFA to spread and dominate the U.S. landscape. Seventy-five years after their introduction, there are five times more RIFA per acre in the U.S. than in their native lands of South America. The native fire ant can help slow the spread of RIFA in North America through competition, and should be protected when possible.

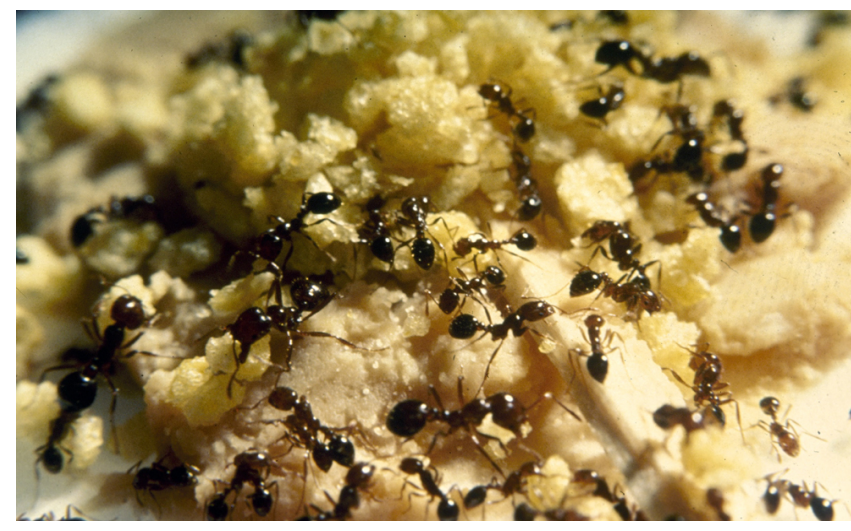

Figure 1. Variable size of red imported fire ant workers. Credits: S.D. Porter, USDA-ARS, www.forestryimages.org (2005).

\section{Red Imported Fire Ant Biology}

\section{Identification}

RIFA can only be microscopically distinguished from other more desirable fire ant species, such as the native fire ant. Like many fire ant species, RIFA range in length from 0.1-0.2 inches and typically

1. This document is WEC 207 and one of a series of the Department of Wildlife Ecology and Conservation, Florida Cooperative Extension Service, Institute of Food and Agricultural Sciences (IFAS), University of Florida. First published: April 2006. Please visit the EDIS Web site at http://edis.ifas.ufl.edu for more publications.

2. Emma Willcox is a Graduate Student and William M. Giuliano is an Assistant Professor and Wildlife Extension Specialist; Department of Wildlife Ecology and Conservation, Cooperative Extension Service, Institute of Food and Agricultural Sciences, University of Florida, Gainesville, FL 32611. 
have a shiny red/orange head and black abdomen. RIFA are polymorphic, meaning that within a colony there are workers of many sizes (Figure 1). Colonies also contain eggs, larvae, and one or more queens. During the mating season, nests may also contain winged-males and virgin queens.

As with other fire ant species, RIFA antennae have ten segments and end in a two-segmented club. The waist (petiole), which attaches the two parts of the body (thorax and abdomen), has two segments. Workers have a stinger at the tip of the abdomen that is clearly visible (Figure 2).

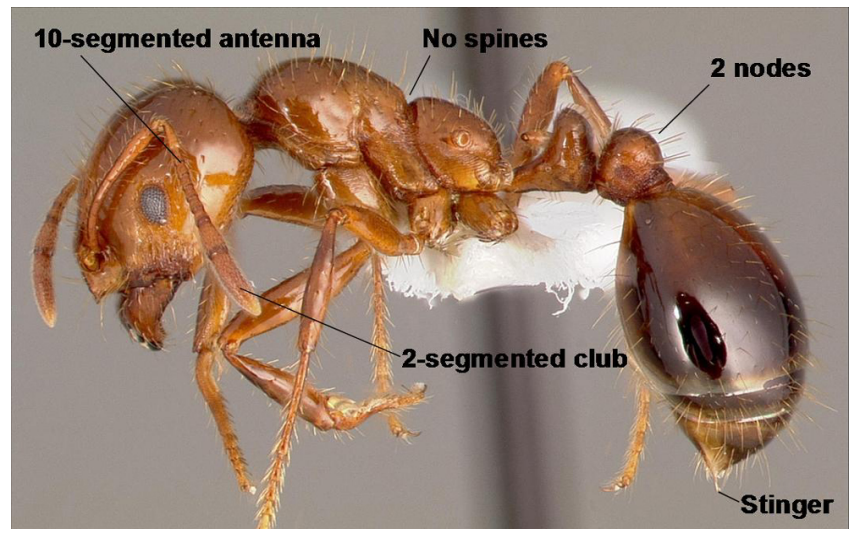

Figure 2. Red imported fire ant worker. Credits: USDA-APHIS PPQ Archives, USDA-APHIS, www.forestryimages.org (2002).

RIFA can be easily identified by the mounds they build and stings they inflict. They have an extremely aggressive nature compared to native fire ants, and when disturbed, workers swarm out of the mound and run up grasses and other vertical surfaces to sting intruders. The native fire ant does not behave in this manner. A RIFA sting causes a painful burning sensation. A few hours to a day after a sting, the RIFA's unique venom forms a white fluid-filled blister on the skin surface. This distinctive blister is very characteristic of RIFA stings (Figure 3 ). If blisters rupture, they can become infected and cause more serious problems.

Your local county extension office can provide assistance identifying RIFA: http://www.ifas.ufl.edu/extension/

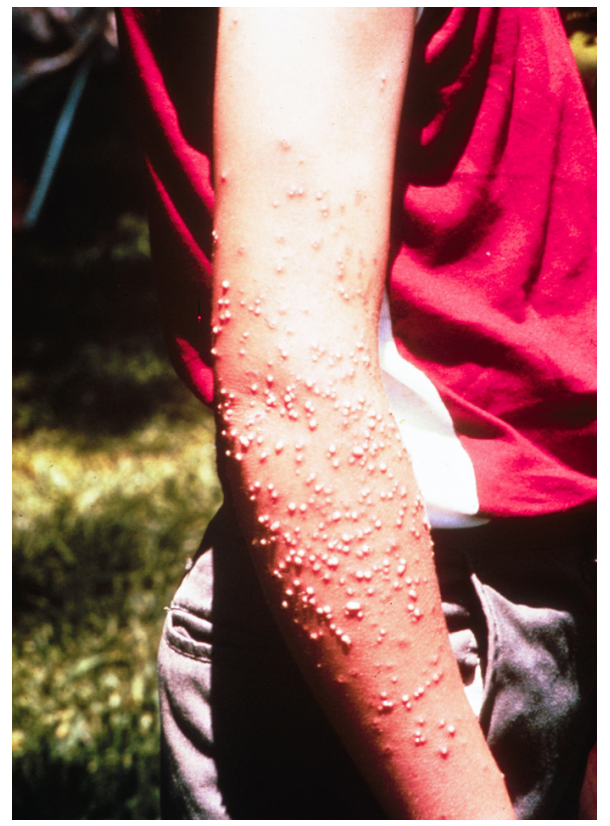

Figure 3. Blisters caused by red imported fire ant stings. Credits: M.S. Blum, University of Georgia, www.forestryimages.org (2003).

\section{Habitat}

RIFA live in colonies contained within large, dome-shaped mounds (Figure 4). Mature mounds range in size from 10-24 inches in diameter and 6-8 inches in height and are generally numerous and easy to see. Each mound may contain in excess of 250,000 ants inhabiting a network of tunnels and chambers. Most foraging for food occurs underground. Unlike most types of ant mounds, those of RIFA have no opening in the center. RIFA leave and enter the mound using a system of subterranean tunnels. As a result, RIFA nests are usually irregular and consist of scattered soil with multiple, obscure entrances. RIFA prefer land that is open and exposed to the sun, often constructing mounds in cultivated fields and pasturelands. In urban areas, they are often found nesting in gardens, yards, parks, playing fields, and cemeteries. Although mounds are characteristic of RIFA, they are not essential and the species can nest in a variety of settings, including the walls of structures and under sidewalks, slabs, and roadways.

During very hot weather, fire ants will move deep into the soil to find cooler temperatures and water. This makes it appear that they have disappeared. However, once the ground becomes moist, they reappear. 


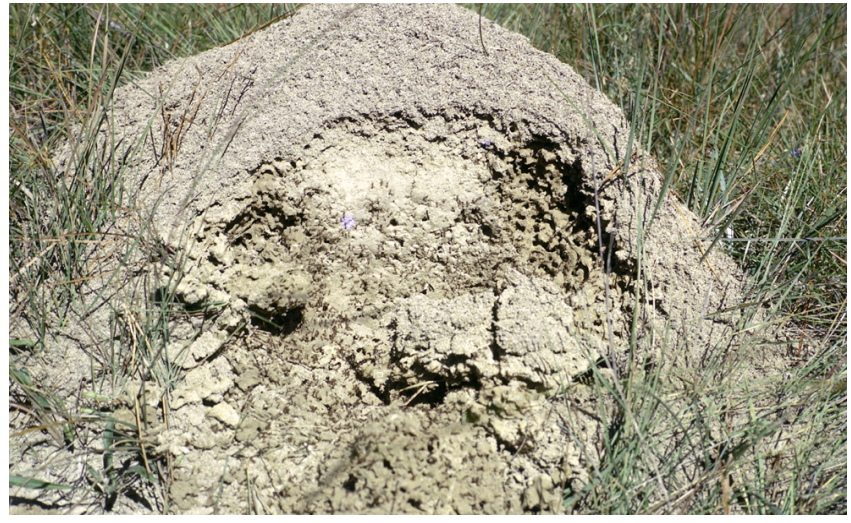

Figure 4. Red imported fire ant mound. Credits: USDA-APHIS PPQ Archives, USDA-APHIS, www.forestryimages.org (2002).

\section{Life Cycle}

The RIFA life cycle is complex. Eggs develop to form white, legless larvae. These larvae pupate before emerging as adults (Figure 5). Fire ants reproduce during mating flights. On warm days during spring and summer, when the temperature is above $72^{\circ} \mathrm{F}$, swarms of winged-males and virgin queens take flight and mate several feet above the ground. After mating, the male dies. The mated queens drop back to the ground where they lose their wings and construct a brood cell, 1-2 inches below the soil surface. Often, multiple queens will share a cell, but normally only one survives to establish a colony.

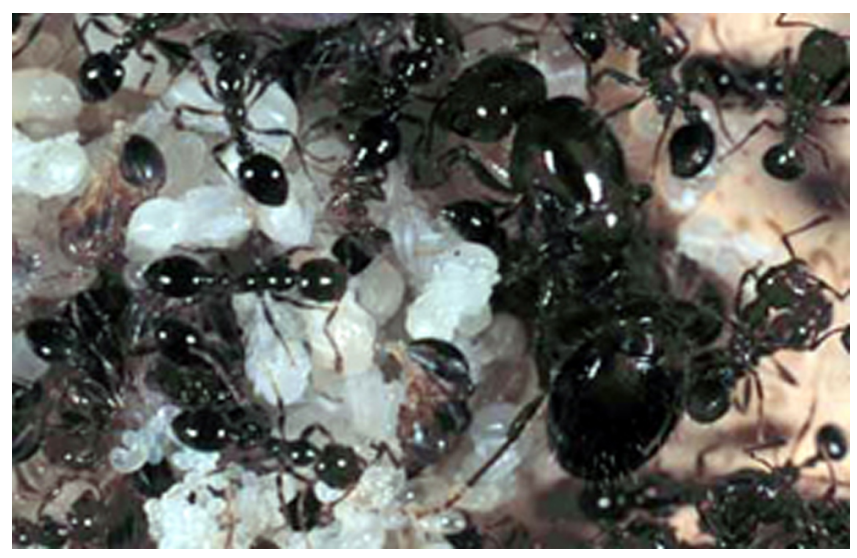

Figure 5. Fire ant queen with workers and larvae. Credits: S.D. Porter, USDA-ARS (2003).

Within the brood cell, the queen initially deposits 10-15 eggs that hatch within 7-10 days. Queens do not forage for food but feed the first larvae using trophallaxis (the mouth-to-mouth exchange of regurgitated, digested food). These first larvae develop into adult workers and take on the task of foraging for food and maintaining the nest. It is the responsibility of the workers to provide food to the queen so that she can feed subsequent larvae.

New colonies grow rapidly, and within 6 months, new workers begin to emerge daily. A healthy RIFA queen lives up to 7 years and may produce 1,600 eggs per day. In the U.S., a large colony may contain multiple queens (polygyne colony). Polygyne colonies contain 100 to 1000 mounds per acre. This is equivalent to 40 million ants per acre. It is rare to see multiple queen colonies in RIFA's native South America. In South America, most colonies contain a single queen (monogyne colony). Monogyne colonies contain approximately 7 million ants per acre, corresponding to 20-80 mounds per acre.

For additional information on RIFA biology: http://edis.ifas.ufl.edu/IN352

\section{Impacts of Red Imported Fire Ants on Wildlife}

RIFA are omnivorous, feeding on both animal and plant material. However, insects appear to be their preferred food source. They will tend and guard some species of sucking insect, such as aphids, which in return provide them with a nutritious, sugary solution known as honeydew.

The introduction of RIFA has resulted in the exclusion of many native ant species through competition and predation. They have also eliminated food supplies used by some wildlife species. RIFA are attracted to wildlife species nesting under or on the ground and in low trees. Species that breed and live in open habitats are more vulnerable than species living in closed-canopied habitats, which tend to have much lower fire ant densities. Certain animals are very susceptible to predation by RIFA, and multiple stings can result in the death of small bodied animals, dramatically reducing populations of some wildlife species. In addition, fire ants can cause disfigurement and disablement of larger animals. Certain types of wildlife, such as deer, ground-nesting birds, and reptiles are especially vulnerable to RIFA during and soon after birth or hatching. And, adult animals may be displaced by irritation resulting from stings and can be affected by reductions in food availability. 


\section{Impacts on Reptiles and Amphibians}

A number of traits make reptiles particularly susceptible to RIFA. These include egg-laying and the disturbance associated with this activity, as well as delayed hatchling emergence. RIFA stings can reduce reptile survival by preventing weight gain, altering behavior, and changing foraging patterns and habitat use. For example, in the case of alligators (Alligator mississippiensis), hatchlings that emerge from nesting material containing red imported fire ants exhibit significantly less weight gain and have reduced survival. Alligator nests that contain RIFA also receive less maintenance by adult female alligators.

Many turtle species are impacted by fire ants, and irritation from RIFA stings can cause adults to abandon nesting attempts. RIFA will also prey on turtle hatchlings just below the surface of the ground and as they emerge. Box turtles (Terrapene carolina) appear to be particularly susceptible to RIFA predation due to their defensive reactions. When disturbed, box turtles close off their shells and become immobile. Even a tightly closed box turtle shell has gaps large enough for RIFA to penetrate, and the turtle's immobility allows more fire ants to swarm over it. RIFA predation of hatchling and juvenile gopher tortoises (Gopherus polyphemu), a species of special concern in Florida, has also been observed.

Hatchlings of many turtle species, including Florida red-bellied turtles (Pseudomys nelsoni), do not emerge from their nest until most or all of the clutch has hatched, increasing their vulnerability to RIFA. RIFA cannot penetrate intact eggs. However, as soon as turtle hatchlings pip (crack open the shell of their egg) RIFA enter, stinging and consuming them. RIFA have even been observed to establish underground foraging tunnels to turtle nests and "monitor" eggs for signs of hatching. The average hatchling release rate of loggerhead turtles (Caretta caretta) and green turtles (Chelonia mydas), in Florida and Georgia, can be up to $15 \%$ lower in nests infested with fire ants. Many individuals are stung and consumed by RIFA before leaving the nest. Those that do emerge have often been blinded and sustained injuries to flippers and heads as a result of stinging, which can reduce their survival.
RIFA have been implicated in the declines of the Texas horned lizard (Phrynosoma cornutum) and two species of snake found in Florida, the southern hognose snake (Heterodon simus) and peninsular intergrade kingsnake (Lampropeltis getula floridanus). For each species, their decline coincided with the invasion of RIFA. It is thought RIFA may impact these reptile species by reducing the availability of food and attacking and preying upon incubating eggs and hibernating individuals.

Little research has been conducted on the effects of RIFA on amphibians. However, like reptiles, they would appear to be a highly vulnerable animal group with eggs and young individuals particularly susceptible to fire ant consumption and stinging.

\section{Impacts on Birds}

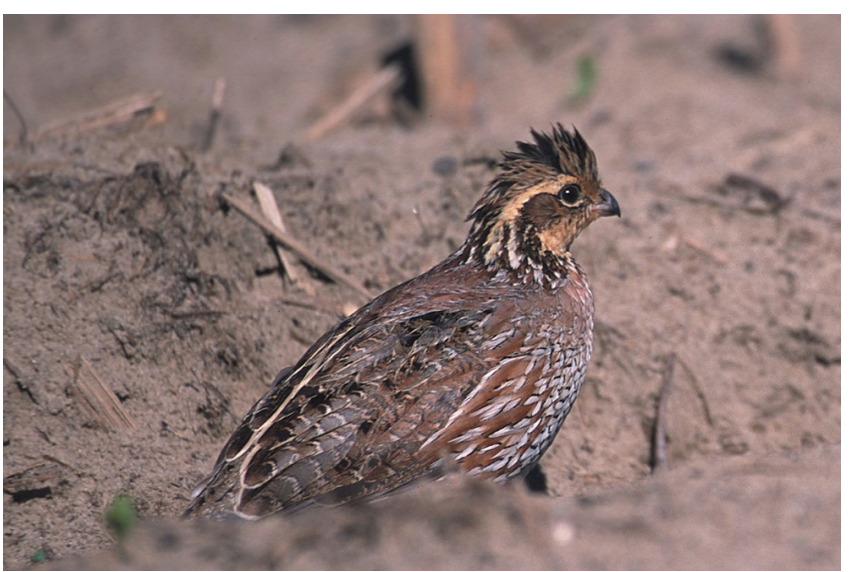

Figure 6. Red imported fire ants can almost completely eliminate ground-nesting birds such as the bobwhite quail. Credits: J. Vanuga, USDA-NRCS, www.forestryimages.org (2003).

RIFA can completely eliminate ground-nesting birds in a given area. The northern bobwhite quail (Colinus virginianus; Figure 6), an important game species, has been the focus of much research on the impacts of RIFA. RIFA may be one of the reasons for the observed decline in quail numbers in Florida and across much of the southeastern U.S. over the past 10 years. RIFA impact bobwhite quail by stinging and consuming piping young. Even after they hatch, individuals stung by fire ants have reduced survival. In one study, $38 \%$ of bobwhite chick deaths were attributed to RIFA stings. If chicks do survive being stung, their growth is often stunted, resulting in a lower body mass. A lower body mass 
can potentially increase their risk of mortality from other factors such as predation, disease, starvation, or exposure.

\section{Loggerhead shrike (Lanius ludovicianus)} numbers are also often lower in habitats invaded by fire ants. These declines may be a result of competition with RIFA for food, primarily insects. RIFA have also been reported causing mortality and declines in barn swallows (Hirundo rustica), crested caracaras (Caracara plancus), common ground doves (Columbina passerine), blue-grey gnatcatchers (Polioptila caerulea), eastern towhees (Pipilo erythrophthalamus), indigo buntings (Passerine cyanea), northern cardinals (Cardinalis cardinalis), and yellow-billed cuckoos (Coccyzus americanus) in certain areas. The causes of mortality and reasons for decline vary between species but are usually a result of stinging, predation of young, or competition for food resources.

Waterbirds such as the least tern (Sterna antillarum), great egret (Casmerodius albus), snowy egret (Egretta thula), roseate spoonbill (Ajara ajara), laughing gull (Larus atricilla), black rail (Laterallus jamaicensis), great blue heron (Ardea herodis), and tricolored heron (Egretta tricolor), all of which can be found in Florida, can also be severely impacted by RIFA. One Texas study showed that, during the warm summer months of June and July when RIFA are most active, ant infestation was responsible for up to a $92 \%$ reduction in offspring survival of many of these waterbirds.

\section{Impacts on Mammals}

The impacts of fire ants on mammals have been most clearly documented in deer. The presence of RIFA in an area reduces the number of deer fawns surviving to maturity. In the presence of danger, deer fawns freeze. This allows RIFA to attack, causing blindness or debilitating injury (Figure 7). The irritation caused by RIFA stings may also result in increased fawn movements, heightening their risk of predation by animals such as the coyote. If increased movement occurs during the day when fawns would normally remain hidden, this could further increase their predation risk. Similar effects on the young of other mammal species could be possible. RIFA are also thought to be a threat to small mammals such as mice, voles, and squirrels due to their small size and tendency of many to live below ground.

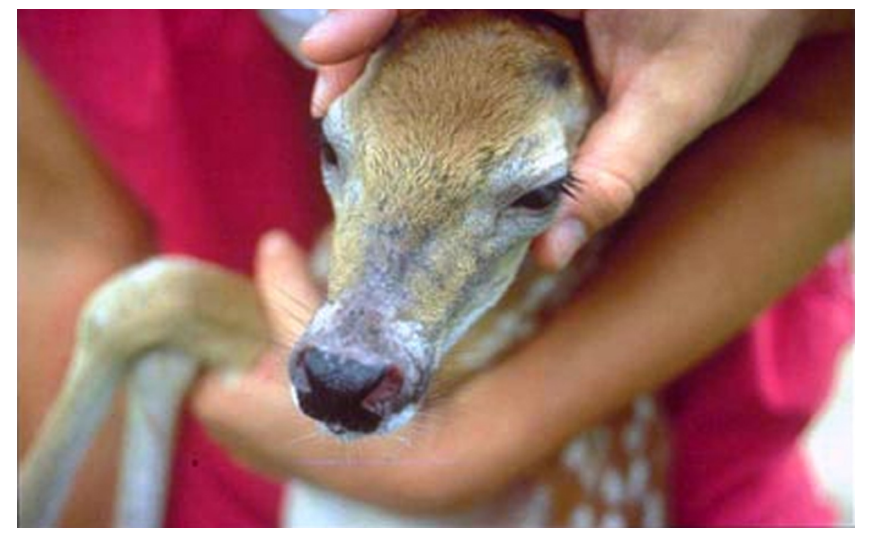

Figure 7. Deer fawn with scars on its head from red imported fire ant stings. Credits: B.M. Drees, Texas A and M University (2004).

For additional information on RIFA impacts on wildlife:

C.R. Allen, D.M. Epperson and A.S. Garmestani. 2004. Red imported fire ant impacts on wildlife: A decade of research. American Midland Naturalist. 152: $88-103$

http://fireant.tamu.edu/materials/factsheets_pubs/pdf/ FAPFS006.2002rev.pdf

\section{Red Imported Fire Ant Control}

Many methods are employed in an attempt to control the abundance and spread of RIFA. Some of these methods are new and still being experimentally tested, while others have been used for many years with varying degrees of success.

One of the more traditional approaches involves the use of mound drenches, whereby individual mounds are treated with insecticide in an attempt to kill all ants inside. An alternative approach is to use bait-formulated insecticides. These baits are collected by foraging worker ants and taken back to the colony where they are distributed. The bait is fed to the queen and she is killed or prevented from producing viable eggs.

A relatively new control method involves the release and spread of RIFA's natural enemies. These are known as biological control organisms. Biological control organisms kill fire ants in their 


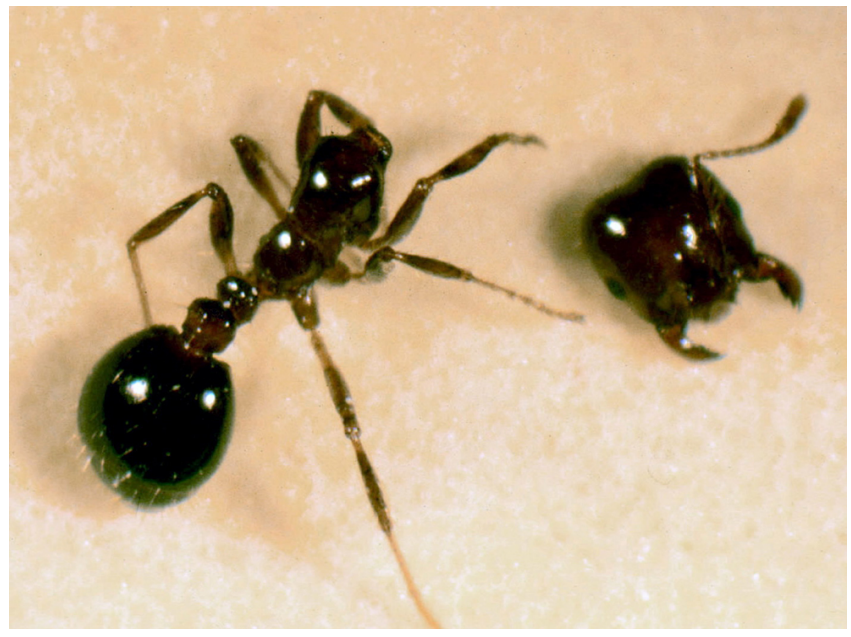

Figure 8. Red imported fire ant decapitation. Credits: S.D. Porter, USDA-ARS, www.forestryimages.org (2005).

native South America but have only recently been brought to the U.S. The effectiveness of two of these biological control organisms is currently being tested in Florida. The first is the decapitating fly of the genus Pseudacteon. These attack fire ant workers and cause them to hide instead of feed, weakening the colony. When they do catch RIFA, female flies lay eggs which develop inside the fire ant head, causing it to fall off. Adult flies emerge from the severed head and attack other fire ants (Figure 8). The second biological control agent is a fire ant disease (Thelohania solenopsae). The disease is introduced into colonies by placing infected RIFA larvae in the mound. The disease is caused by a protozoan which weakens the colony. Weakened colonies result in fewer fire ant reproductives to start new colonies.

For additional information on RIFA control:

http://fireant.ifas.ufl.edu/index.htm

http://fireant.tamu.edu/materials/factsheets_pubs/pdf/ FAPFS009.2002rev.pdf

http://fireant.tamu.edu/materials/factsheets_pubs/pdf/ FAPFS005.2002rev.pdf

Other useful websites:

http://www.aphis.usda.gov/ppq/ispm/fireants/

http://uts.cc.utexas.edu/ gilbert/research/fireants/ faq.html 